\title{
Origem e distribuição do nervo femoral do mocó, Kerodon rupestris (Cavidae) ${ }^{1}$
}

\author{
Gleidson B. Oliveira² ${ }^{2}$ José F.G. Albuquerque ${ }^{2}$, Marcio N. Rodrigues², A.L.C. \\ Paiva $^{2}$, Carlos E.B. Moura ${ }^{3}$, Maria A. Miglino ${ }^{4}$ e Moacir F. Oliveira ${ }^{2 *}$
}

\begin{abstract}
Oliveira G.B., Albuquerque J.F.G., Rodrigues M.N., Paiva A.L.C., Moura C.E.B., Miglino M.A. \& Oliveira M.F. 2011. [Origin and distribution of femoral nerve of the rocky cavy, Kerodon rupestris (Cavidae).] Origem e distribuição do nervo femoral do mocó, Kerodon rupestris (Cavidae). Pesquisa Veterinária Brasileira 31(Supl.1):84-88. Departamento de Ciências Animais, Universidade Federal Rural do Semi-Árido, Bairro Pres. Costa e Silva, Mossoró, RN 59625-900, Brazil. E-mail: moacir@ufersa.edu.br

Rock cavy (Kerodon rupestris Wied, 1820), a rodent mammal from the Cavidae family is highly adapted to conditions of heat and shortage of water and food, mainly in the periods of great drought that periodically devastate the semi-arid of Northeast Brazil. In the literature, few data are found regarding the functional anatomy of the rock cavy, especially involving the anatomy of the nervous system. We aimed to investigate the origin of the femoral nerve close to the intervertebral foramina, its location and distribution for the musculature of the legs, to verify its importance to support further studies for wild animal clinics, and to contribute for the comparative neuro-anatomy. Ten adult rock cavies of different ages were used ( 4 males and 6 females), that had died in the Wild Animal Multiplication Center (Cemas) of the Rural Federal University of the Semi-Arid, Mossoró. After the fixation in aqueous solution of $10 \%$ formalin, the dissection of the abdominal cavity of the animals was accomplished for complete visualization of the femoral nerve. Variations were verified in the number of lumbar vertebrae, as seven animals (70\%) had seven lumbar vertebrae, and three $(30 \%)$ only six, altering the origin of the nerve. On the right side, in four animals $(40 \%)$ the femoral nerve originated from ventral branches of L5 to L6, four $(40 \%)$ from L5 to L7, and in two (20\%) from L4 to L6. On the left side, in five animals (50\%) the femoral nerve originated from the ventral branches of L5 to L6, in three (30\%) from L5 to L7, and two (20\%) also from L4 to L6.
\end{abstract}

INDEX TERMS: Kerodon rupestris, rock cavy, femoral nerve, lumbosacral plexus.

RESUMO.- 0 mocó (Kerodon rupestris Wied,1820), um mamífero roedor da família Cavidae, que se assemelha bastante ao preá, é um animal altamente adaptado às condições de calor e de escassez de água e de alimento, principalmen-

\footnotetext{
${ }^{1}$ Recebido em 16 de julho de 2011.

Aceito para publicação em 12 de dezembro de 2011.

${ }^{2}$ Departamento de Ciências Animais, Universidade Federal Rural do Semi-Árido (UFERSA), Cx. Postal 137, BR $110 \mathrm{Km} \mathrm{47,} \mathrm{Bairro} \mathrm{Pres.} \mathrm{Costa}$ e Silva, Mossoró, RN 59625-900, Brasil. *Autor para correspondência: moacir@ufersa.edu.br

${ }^{3}$ Departamento de Morfologia, Universidade Federal do Rio Grande do Norte, Cx. Postal 1524, Campus Universitário Lagoa Nova, Natal, RN 59072-970, Brasil.

${ }^{4}$ Departamento de Cirurgia, Universidade de São Paulo, Av. Prof. Dr. Orlando Marques de Paiva 87, Cidade Universitária, São Paulo, SP 05508270, Brasil.
}

te nos períodos das grandes secas que assolam periodicamente a região do semi-árido nordestino. Verifica-se que na literatura há escassez de dados referentes à anatomia funcional dos mocós, em especial de trabalhos envolvendo a anatomia do sistema nervoso. Visando conhecer a origem do nervo femoral junto aos forames intervertebrais, sua localização e distribuição pelo membro pélvico, a musculatura envolvida em seu trajeto, a importância desse estudo para clínica de animais silvestres e contribuir para o desenvolvimento da neuroanatomia comparada, procedeu-se esta pesquisa, na qual foram utilizados dez animais adultos de diferentes idades (4 machos e 6 fêmeas) que vieram a óbito no Centro de Multiplicação de Animais Silvestres (Cemas) da Universidade Federal Rural do Semi-Árido (Ufersa). Os animais foram fixados em solução aquosa de 
formaldeído a $10 \%$ e posteriormente tiveram a cavidade abdominal dissecada até a completa visualização do nervo femoral. Foram verificadas variações no número de vértebras lombares nos animais, entre seis (30\%) e sete (70\%) vértebras, alterando, conseqüentemente, a origem do nervo. No antímero direito, verificou-se que em $40 \%$ dos animais o nervo femoral originava-se de ramos ventrais de $\mathrm{L}_{5} \mathrm{~L}_{6}$, em $40 \%$ de $\mathrm{L}_{5} \mathrm{~L}_{6} \mathrm{~L}_{7}$ e em $20 \%$ de $\mathrm{L}_{4} \mathrm{~L}_{5} \mathrm{~L}_{6}$. Já no esquerdo $50 \%$ dos exemplares o nervo femoral foi formado de raízes ventrais de $\mathrm{L}_{5} \mathrm{~L}_{6}$, em $30 \%$ de $\mathrm{L}_{5} \mathrm{~L}_{6} \mathrm{~L}_{7}$ e em $20 \%$ de $\mathrm{L}_{4} \mathrm{~L}_{5} \mathrm{~L}_{6}$.

TERMOS DE INDEXAÇÃO: Kerodon rupestris, mocó, nervo femoral, plexo lombossacral.

\section{INTRODUÇÃO}

0 mocó (Kerodon rupestris Wied, 1820) é um mamífero roedor (ordem Rodentia), da família dos cavídeos e da subfamília Caviinae muito parecido com o preá, porém, maior e possuindo particularidades morfológicas, fisiológicas e comportamentais bem diferentes. 0 mocó é um animal rupícola (vive nas rochas), não fossório, desprovidos de cauda e dentes caninos, apresentam olhos grandes, orelhas curtas, cabeça com focinho longo e estreito, quatro longos dentes incisivos, que são desprovidos de raiz e com crescimento contínuo, possuem longas pernas propulsoras, de unhas rombas sobre coxins espessos que lhe permitem subir com facilidade em pedras e árvores. A superfície dorsal é cinzento-clara, agrisalhada; a parte traseira do corpo é avermelhada e a superfície ventral, branco-amarelada, apresentando a pelagem da garganta de cor branca viva. Alimenta-se de folhas, brotos, ramos, frutos, cascas de árvores, raízes e tubérculos (Mendes 1945). Os mocós têm o seu habitat nos serrotes pedregosos, nas fraldas de serra onde são abundantes blocos de pedras. Eles procuram abrigo pelas junturas das pedras ou, por vezes, sob as pedras, escavando ou aperfeiçoando galerias. Saem à tardinha ou à noite em busca de alimento, catam folhas da vegetação rasteira ou dos interstícios das pedras ou sobem às árvores e vão colher os brotos das pontas dos galhos (Moojen 1952).

No Brasil, o mocó já vem sendo criado em cativeiro, com o intuito de fornecer alimento, preservar a espécie e proporcionar o desenvolvimento de pesquisas nesses animais. Todavia, verifica-se que na literatura há carência de dados referentes à anatomia funcional dos mocós e em especial de trabalhos envolvendo a anatomia do sistema nervoso e em especifico, o nervo femoral. Outros sistemas corpóreos foram estudados no mocó, como rede vascular (Queiroz et al. 2011) e biologia da reprodução (Oliveira et al, 2006, Francioli et al, 2011)

O nervo femoral inerva o quadríceps da coxa e ao nível da tuberosidade pré-púbica, sua lesão pode ocasionar paralisia (König \& Liebich 2004). A lesão grave deste nervo, embora, relativamente rara, determina sérias conseqüências como a paralisia do músculo quadríceps, impedindo a fixação da articulação do joelho e desta forma tornando todo membro incapaz de suportar peso e a inibição do reflexo patelar, não sendo possível compensar esta deficiência (Dyce et al. 2004). Além do mais, a lesão deste nervo ocasiona a perda de sensibilidade na face medial da coxa, do joelho, da perna e da pata (Chrisman 1985).

A paralisia femoral (paralisia do quadríceps) causa a insensibilidade do músculo quadríceps femoral. A função de suporte na articulação do joelho fica comprometida, com flexão superficial da mesma. Possíveis causas de paralisia femoral são o uso de bandagens impróprias nos eqüinos e fraturas pélvicas (König \& Liebich 2004).

Radostits et al. (2000), relata a paralisia do nervo femoral em bezerros, com histórico de distocia. A tração utilizada para o nascimento desses bezerros causa hiperextensão do fêmur e distensão do músculo quadríceps com seus suprimentos sanguíneo e nervoso. Na maioria dos casos, o nervo femoral direito é o acometido. Tais bezerros, alguns dias após o nascimento, apresenta no membro acometido o músculo quadríceps atrofiado, podendo a patela ser facilmente luxada.

Lesões dos segmentos $\mathrm{L}_{4}$ a $\mathrm{L}_{6}$ da medula espinal resultam na dessensibilização cutânea da superfície medial do membro pélvico, e num reflexo patelar diminuído ou ausente (Smith 1930).

0 nervo femoral nas espécies domésticas, de um modo geral, surge na parte cranial (L4-L6) do plexo lombossacral e percorre um caminho através do músculo psoas para alcançar o espaço entre o ângulo dorso-caudal do flanco e o músculo íliopsoas. Este nervo é acompanhado pela artéria femoral e pelas veias ilíacas externas e, ao entrar na coxa, corre numa posição protegida entre o músculo sartório e o pectínio. Logo emite o nervo safeno e, após um curto trajeto, mergulha entre os músculos reto femoral e vasto medial, para atender à massa do músculo quadríceps (Dyce et al. 2004). Além do quadríceps da coxa, o nervo femoral é responsável pela inervação dos músculos íliopsoas, ilíaco (Getty 1981a,b, König \& Liebich 2004), sartório (Chrisman 1985), psoas maior e pectíneo (Frandson et al. 2005).

Objetivou-se, neste trabalho, descrever, em mocós, particularidades sobre a formação do nervo femoral e a musculatura envolvida em seu trajeto, fornecendo assim dados morfológicos para anatomia comparada, bem como para a clínica médica e clínica cirúrgica, especialmente de animais silvestres.

\section{MATERIAL E MÉTODOS}

Foram utilizados 10 mocós (quatro machos e seis fêmeas) adultos que morreram por causas naturais no Centro de Multiplicação de Animais Silvestres (Cemas/Ufersa), criadouro registrado junto ao IBAMA com o no 14.492.004.

Os animais foram fixados por meio de solução aquosa de formaldeído a $10 \%$, através da artéria carótida comum, sendo as peças mantidas submersas em uma solução de formaldeído de mesma concentração por um período mínimo de 48 horas antes do início da dissecação. Logo após, realizou-se as dissecações para exposição do nervo femoral, utilizando-se estereoscópio de Zeiss, sempre que necessário. Os animais foram colocados em decúbito dorsal, eviscerados e em seguida realizada a remoção dos músculos psoas maior e psoas menor, possibilitando a completa visualização das raízes ventrais do nervo femoral, junto aos forames intervertebrais ou vertebrais laterais, de ambos os antímeros. Por fim, foram analisadas as distribuições dos ramos musculares dos nervos femorais em seus respectivos antímeros, na região medial 
da coxa, sendo que para este fim, foi necessário rebater o músculo sartório. Para facilitar a visualização do nervo femoral, foi colocado sobre o mesmo, algodão embebido com peróxido de hidrogênio a 20 volumes, permanecendo por 12 horas seguidas.

A nomenclatura adotada para descrição dos resultados foi da International Commitee on Veterinary Gross Anatomical Nomenclature (1994).

Os dados foram compilados em tabelas e expressos em desenhos esquemáticos e fotos, sendo a análises estatísticas por percentagem e desvio padrão simples.

\section{RESULTADOS}

Foram verificadas variações no número de vértebras lombares do mocó, sendo que em sete animais $(70 \% \pm 6,7 \%)$ apresentavam sete vértebras lombares e três $(30 \% \pm 6,7 \%)$ mostraram apenas seis vértebras lombares.

Com a variação no número de vértebras lombares no mocó, a origem das raízes do nervo femoral apresentou-se distintas comparando os mesmos dentro da espécie, junto aos forames intervertebrais ou vertebrais laterais.

A origem do nervo femoral no mocó, em geral, variou entre o quarto, quinto, sexto e sétimo nervos espinhais lombares, apresentando-se simetricamente na sua origem entre os antímeros direito e esquerdo em $80 \%$ e assimétricos em 20\% dos exemplares (Quadro 1). Assim no antímero direito o nervo femoral originou-se de segmentos de $\mathrm{L}_{5} \mathrm{~L}_{6}$ (Fig.1) em 40\% dos animais, de $\mathrm{L}_{5} \mathrm{~L}_{6} \mathrm{~L}_{7}$ (Fig.2) em $40 \%$ dos animais e de $\mathrm{L}_{4} \mathrm{~L}_{5} \mathrm{~L}_{6}$ (Fig.3) em 20\% dos mocós. Já no antímero esquerdo foi formado pelas raízes ventrais de $\mathrm{L}_{5} \mathrm{~L}_{6}(50 \%)$, de $\mathrm{L}_{5} \mathrm{~L}_{6} \mathrm{~L}_{7}(30 \%)$ e de $\mathrm{L}_{4} \mathrm{~L}_{5} \mathrm{~L}_{6}(20 \%)$.

Após receber ramos de $\mathrm{L}_{4}$ a $\mathrm{L}_{7}$ que os constituíram, os nervos femorais direito e esquerdo percorreram um caminho entre os músculos psoas maior e psoas menor para

Quadro1. Ramos ventrais que participam da formação do nervo femoral nos antímeros direito (AD) e esquerdo (AE) no mocó

\begin{tabular}{|c|c|c|c|c|c|}
\hline \multicolumn{2}{|c|}{ Origem } & \multicolumn{2}{|c|}{ Frequência } & \multicolumn{2}{|c|}{$\%$} \\
\hline $\mathrm{AD}$ & $\mathrm{AE}$ & $\mathrm{AD}$ & $\mathrm{AE}$ & $\mathrm{AD}$ & $\mathrm{AE}$ \\
\hline L4L5L6 & L4L5L6 & 2 & 2 & 20 & 20 \\
\hline L5L6 & L5L6 & 4 & 5 & 40 & 50 \\
\hline L5L6L7 & L5L6L7 & 4 & 3 & 40 & 30 \\
\hline
\end{tabular}
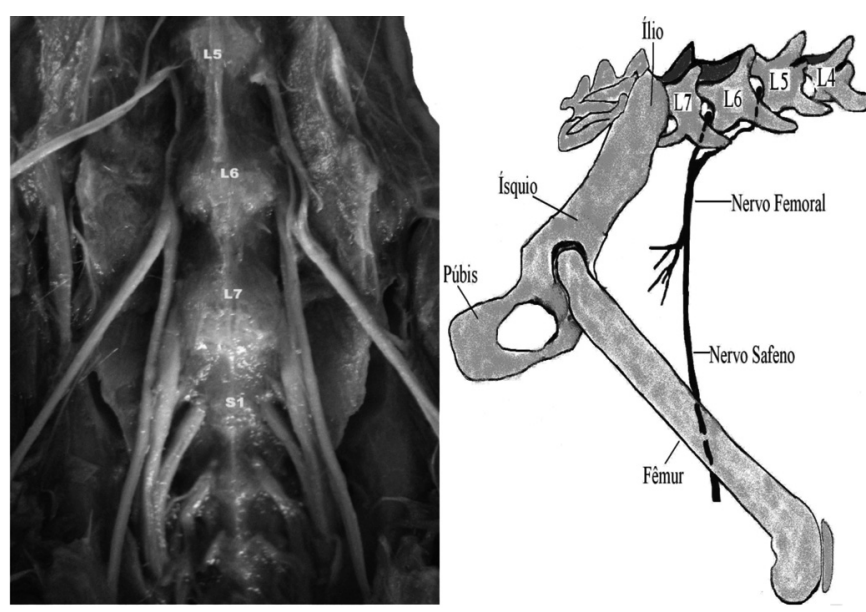

Fig.1. Origem do nervo femoral $\mathrm{L}_{5} \mathrm{~L}_{6}$ e sua representação esquemática (vista lateral) à direita.
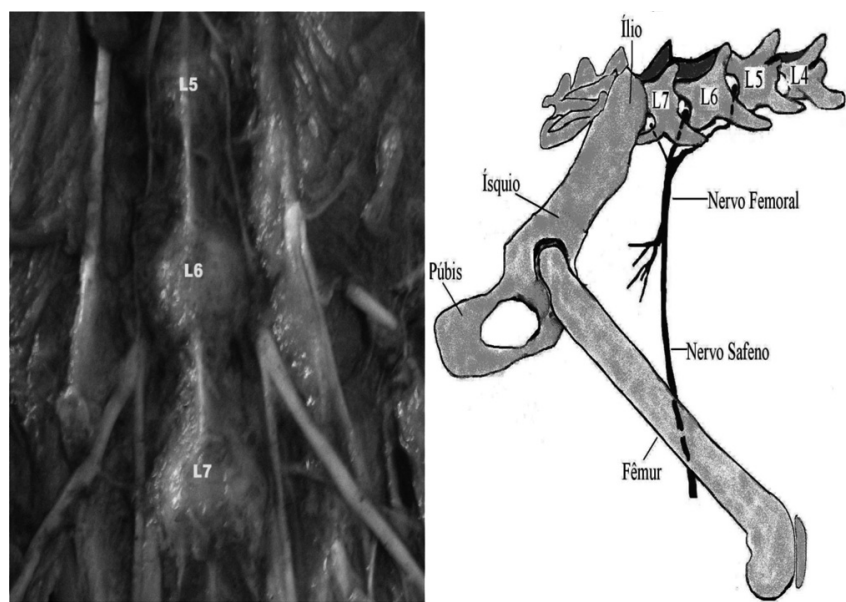

Fig.2. Origem do nervo femoral em $\mathrm{L}_{5} \mathrm{~L}_{6} \mathrm{~L}_{7}$ e sua representação esquemática (visão lateral) à direita.
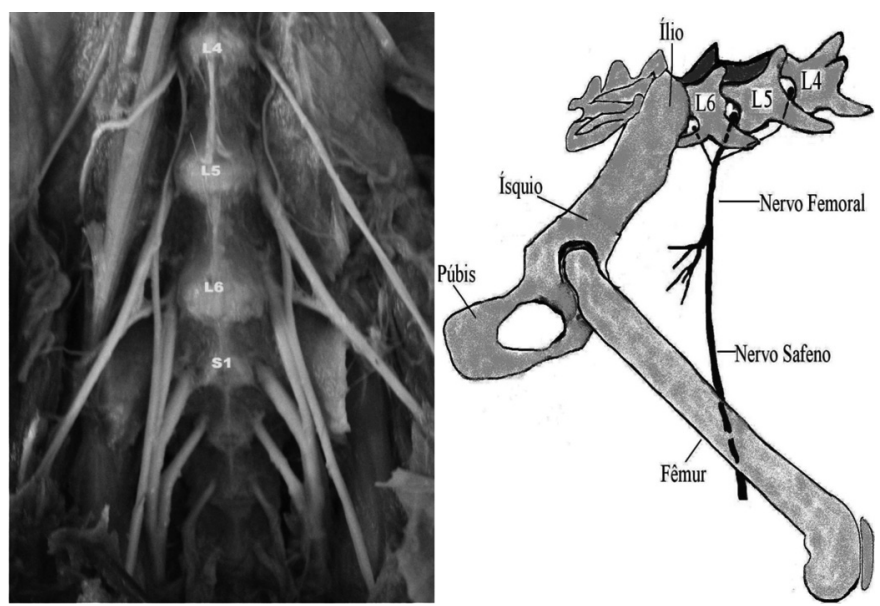

Fig.3. Origem do nervo femoral em $\mathrm{L}_{4} \mathrm{~L}_{5} \mathrm{~L}_{6}$ e sua representação esquemática (visão lateral) à direita.

alcançar o espaço entre o ângulo dorso-caudal do flanco e o músculo íliopsoas, destinando-se medialmente à musculatura da coxa, ramificando-se e prosseguindo com o nervo safeno na face medial proximal da coxa. Em seu curto trajeto o nervo femoral emitiu ramos para os músculos ilíaco, pectíneo, sartório e para o quadríceps femoral.

Os nervos femorais emitiram ramos ao músculo ilíaco que variaram de um a três nos antímero direito e esquerdo. Em seguida, atingindo a coxa, inervou o músculo pectíneo, sendo que o número de ramos variou de um a três nos dois antímeros. 0 músculo sartório recebeu de um a dois ramos do nervo femoral nos dois antímeros. Ao mergulhar para atender a massa do quadríceps femoral, observou-se que o nervo emitiu de dois a seis ramos no antímero direito e de dois a cinco no esquerdo.

A porcentagem de animais de acordo com o número de ramos do nervo femoral aos músculos ilíaco, pectíneo, sartório e quadríceps femoral está disposta na tabela 2 .

\section{DISCUSSÃO}

Notou-se a correlação entre os resultados obtidos nesta pesquisa com os referidos por Godinho et al. (1985), em que o número de vértebras lombares nas espécies domésti- 


\section{Quadro 2. Freqüência percentual da distribuição do nervo femoral pela musculatura nos antímeros direito (AD) e esquerdo (AE) correspondentes}

\begin{tabular}{|c|c|c|c|c|c|c|}
\hline \multirow[t]{2}{*}{$\begin{array}{c}\text { Distribuição } \\
\text { (Musculatura) }\end{array}$} & \multicolumn{2}{|c|}{$\begin{array}{l}\text { Número de } \\
\text { ramos }\end{array}$} & \multicolumn{2}{|c|}{$\begin{array}{l}\text { Frequência/ } \\
\text { animal }\end{array}$} & \multicolumn{2}{|c|}{$\%$} \\
\hline & $\mathrm{AD}$ & $\mathrm{AE}$ & $\mathrm{AD}$ & $\mathrm{AE}$ & $\mathrm{AD}$ & $\mathrm{AE}$ \\
\hline \multirow[t]{4}{*}{ M. ilíaco } & 0 & 0 & 2 & 2 & 20 & 20 \\
\hline & 1 & 1 & 3 & 2 & 30 & 20 \\
\hline & 2 & 2 & 4 & 4 & 40 & 40 \\
\hline & 3 & 3 & 1 & 2 & 10 & 20 \\
\hline \multirow[t]{5}{*}{ M. quadríceps da coxa } & 2 & 2 & 1 & 3 & 10 & 30 \\
\hline & 3 & 3 & 5 & 3 & 50 & 30 \\
\hline & 4 & 4 & 2 & 3 & 20 & 30 \\
\hline & 5 & 5 & 1 & 1 & 10 & 10 \\
\hline & 6 & 0 & 1 & 0 & 10 & 0 \\
\hline \multirow[t]{3}{*}{ M. pectíneo } & 1 & 1 & 7 & 6 & 70 & 60 \\
\hline & 2 & 2 & 2 & 3 & 20 & 30 \\
\hline & 3 & 3 & 1 & 1 & 10 & 10 \\
\hline \multirow[t]{2}{*}{ M. sartório } & 1 & 1 & 7 & 6 & 70 & 60 \\
\hline & 2 & 2 & 3 & 4 & 30 & 40 \\
\hline
\end{tabular}

cas é variável, influenciando na quantidade de nervos espinhais lombares. No mocó identificou-se a presença de seis e sete vértebras lombares.

Greenaway et al. (2001) e Lacerda et al. (2006), quando fizeram referência ao plexo lombossacral em coelhos e mocós, respectivamente, observaram numa maior freqüência sete vértebras lombares, corroborando com os resultados aqui vistos.

Analisando o número de vértebras lombares nos mamíferos domésticos König \& Liebich (2004) descrevem seis ou sete vértebras lombares para os carnívoros, cinco a sete nos suínos, seis nos bovinos e nos pequenos ruminantes e cinco a sete nos eqüinos. Já Getty $(1981 \mathrm{a}, \mathrm{b})$ relata de seis a sete lombares no suíno, sete no cão e no gato, cinco ou seis no cavalo e seis no bovino. Frandson et al. (2005) descrevem seis lombares para bovinos e eqüinos e seis a sete para suínos.

0 nervo femoral do mocó é constituído pelas raízes ventrais do quinto e sexto nervos lombares, com contribuições variáveis do quarto e sétimo nervos lombares. De uma maneira geral, os Tratados de Anatomia (König \& Liebich 2004, Dyce et al. 2004) descrevem nos animais domésticos que este nervo é formado em $\mathrm{L}_{4}, \mathrm{~L}_{5}$ e $\mathrm{L}_{6}$, situação observada em 20\% dos exemplares. Já Chrisman (1985) menciona que no cão e no gato este nervo é formado pelos segmentos oriundos de $\mathrm{L}_{4}$ e $\mathrm{L}_{5}$. Getty $(1981 \mathrm{a}, \mathrm{b})$ relata este nervo surgindo das raízes ventrais de $\mathrm{L}_{5}$ e $\mathrm{L}_{6}$ no gato, de $\mathrm{L}_{4}$ com contribuições variáveis de $\mathrm{L}_{3}$ e $\mathrm{L}_{5}$ no cão, de $\mathrm{L}_{5} \mathrm{~L}_{6}$ no ovino, de $L_{5}$ e às vezes de $L_{6}$ no caprino, e de $L_{3} L_{4} L_{5}$, podendo receber ainda um fascículo de L6 no eqüino. Getty (1981b) observa no suíno, que o nervo femoral possui uma origem extremamente variável, podendo originar-se do terceiro ao sexto nervo lombar. Porém, na presente investigação, não foi notada a sua origem em $\mathrm{L}_{3}$.

Lacerda et al. (2006) estudando o plexo lombossacral do mocó constataram que o nervo femoral é formado pelo quinto e sexto nervos lombares, com contribuições variáveis de $\mathrm{L}_{4}$ e $\mathrm{L}_{7}$, corroborando com os nossos achados.

Rondini et al. (2005) e Oliveira et al. (2008) observaram que na chinchila (Chinchila lanigera) e no preá (Galea spixii) o nervo femoral origina-se das raízes ventrais de $\mathrm{L}_{5}$ e $\mathrm{L}_{6}$, $\mathrm{se}$ - melhante aos resultados encontrados no mocó. Já Castro et al. (2005) verificaram no lobo-marinho (Arctocephalus australis) que este nervo surge da união dos segmentos $\mathrm{L}_{3} \mathrm{e} \mathrm{L}_{4}$.

Conforme citações de König \& Liebich (2004) e Frandson et al. (2005) nos animais domésticos, o nervo femoral tem curto trajeto e logo, emite ramos para musculatura lombar profunda, para os músculos ilíaco, sartório, psoas maior e quadríceps femoral. Frandson et al. (2005) cita ainda a inervação do músculo pectíneo. Já König \& Liebich (2004) citam ainda, no cão e no gato, a inervação do músculo íliopsoas. Dyce et al. (2004) relatam apenas que o nervo femoral inerva o quadríceps da coxa. Chrisman (1985) menciona que no cão e no gato o nervo femoral é responsável por atender os músculos íliopsoas, quadríceps e sartório. Getty (1981b) relata que no cão este nervo fornece o suprimento motor para o músculo quadríceps da coxa. Diferentemente dos achados em animais domésticos, o nervo femoral do mocó não emitiu ramos para os músculos psoas maior e íliopsoas.

Nos animais silvestres, Castro et al. (2005) e Rondini et al. (2005) observaram no lobo-marinho e na chinchila que o nervo femoral inerva os músculos lombares profundos e quadríceps femoral.

A paralisia do nervo femoral é comentada em animais domésticos por Smith (1930), Chrisman (1985), Radostits et al. (2000), Dyce et al. (2004) e König \& Liebich (2004).

\section{CONCLUSÕES}

No presente estudo, foram encontradas variações no número de vértebras lombares, predominando a presença de sete vértebras, o que influencia a origem do nervo femoral.

Em geral pode-se notar que as raízes do nervo femoral, quanto à origem variaram entre o quarto, quinto, sexto e sétimo nervos espinhais lombares.

Constatou-se ainda que na espécie, o nervo femoral emite ramos para os músculos ilíaco, sartório, pectíneo e principalmente para o quadríceps da coxa, continuando-se com um tronco calibroso, o nervo safeno.

0 estudo deste nervo mostra a contribuição para a Clínica Médica e Clínica Cirúrgica, evitando deste modo, lesões neurológicas.

Agradecimentos.- Ao CNPq/UFERSA pelo fomento à pesquisa.

\section{REFERÊNCIAS}

Castro T.F., Souza D.A.S., Franceschi R.C., Dummer, R.J., Pereira, M.A.M. \& Silva Filho R.P. 2005. Sistematização da inervação Lombo-sacral em Arctocephalus australis. XIV Congresso de Iniciação Científica, Pelotas, RS. Online. Acessado em 3 de maio de 2008. Disponível na internet <http:// www.ufpel.edu.br/cic/2005/arquivos/conteudo_CB.html\#00747>.

Chrisman C.L. 1985. Neurologia dos Pequenos Animais. Roca, São Paulo. 432p.

Dyce K.M., Sack W.O. \& Wensing C.J. 2004. Tratado de Anatomia Veterinária. $3^{\underline{a}}$ ed. Editora Elsevier, Rio de Janeiro. 813p.

Franciolli A.L.R., Ambrósio C.E., Oliveira M.F., Morini A.C., Favaron P.O., Machado M.R.F. \& Miglino M.A. 2011. Os histricomorfos sul-americanos: uma análise comparativa do desenvolvimento embriológico. Pesq. Vet. Bras. 31(5):441-446.

Frandson R.D., Wilke W.L. \& Fails A.D. 2005. Anatomia e fisiologia dos animais da fazenda. 6 ed. Editora Guanabara Koogan, Rio de Janeiro. 454p. 
Getty R. 1981a. Anatomia dos Animais Domésticos. Vol.1. 5a ed. Editora Interamericana, Rio de Janeiro. 1134p.

Getty R. 1981b. Anatomia dos Animais Domésticos. Vol.2. 5a ed. Editora Interamericana, Rio de Janeiro. 863p.

Godinho H.P., Cardoso F.M. \& Nascimento J.F. 1985. Anatomia dos Ruminantes Domésticos. Instituto de Ciências Biológicas, Universidade Federal de Minas Gerais, Belo Horizonte. 526p.

Greenaway J.B., Partlow G.D., Gonsholt N.L. \& Fisher K.R.S. 2001. Anatomy of the lumbosacral spinal cord in rabbits. J. Am. Anim. Hosp. Assoc. 37(1):27-34.

International Committee on Veterinary Gross Anatomical Nomenclatura 1994. Nomina Anatômica Veterinaria. $4^{\text {th }}$ ed. New York. 198p.

König H.E. \& Liebich H.G. 2004. Anatomia dos Animais Domésticos: texto e atlas colorido. Vol.2. Editora Artmed, Porto Alegre. 399p.

Lacerda P.M.O., Moura C.E.B., Miglino M.A., Oliveira M.F. \& Albuquerque J.F.G. 2006. Origem do plexo lombossacral de mocó (Kerodon rupestris). Braz. J. Vet. Res. Anim. Sci. 43(5):620-628.

Mendes B.V. 1987. Plantas e animais para o Nordeste. Editora Globo, Rio de Janeiro. 167p.

Moojen J. 1952. Os Roedores do Brasil. Instituto Nacional do Livro, Ministério de Educação e Saúde, Rio de Janeiro. 214 p.
Oliveira G.B., Albuquerque J.F.G., Oliveira M.F., Rodrigues M.N., Sousa R.S., Sousa E.S. \& Miglino M.A. 2008. Source and distribution of the lumbosacral plexus in spix's yellow-toothed cavy (Galea spixii spixii). XXIII Congresso Brasileiro de Anatomia, Belém, PA. CD-ROM.

Oliveira M.F., Carter A.M., Bonatelli M., Ambrosio C.E. \& Miglino M.A. 2006. Placentation in the rock cavy, Kerodon rupestris (Wied). Placenta. 27(1):87-97

Queiroz P.V.S., Moura C.E.B., Lucena J.A., Oliveira M.F. \& Albuquerque J.F.G. 2011. Cranial and caudal mesenteric arteries in rock cavy Kerodon rupestris (Wied, 1820).] Artérias mesentéricas cranial e caudal em mocós Kerodon rupestris (Wied, 1820). Pesq. Vet. Bras. 31(7):623-626.

Radostits O.M., Gay C.C., Blood D.C. \& Hinchicliff K.W. 2000. Clínica Veterinária: um tratado de doenças dos bovinos, ovinos, suínos, caprinos e eqüinos. 9a ed. Editora Guanabara Koogan, Rio de Janeiro. 1737p.

Rondini B.T., Gamba C.O., Pereira R.L., Wulff M.L., Pereira M.A.M. \& Rickes E.M. 2005. Sistematização dos territórios nervosos do plexo lombo-sacral em chinchilla lanígera. XIV Congresso de Iniciação Científica, Universidade Federal de Pelotas, Pelotas, RS. Online. Acessado em 3 de maio de 2008. Disponível na internet <http://www.ufpel.edu.br/cic/2005/ arquivos/conteudo_CB.html\#00747>.

Smith B.P. 1993. Tratado de Medicina Interna de Grandes Animais: moléstias de eqüinos, bovinos, ovinos e caprinos. Editora Manole, São Paulo. 